\title{
'Anti-vax' noise will jeopardise HPV breakthrough
}

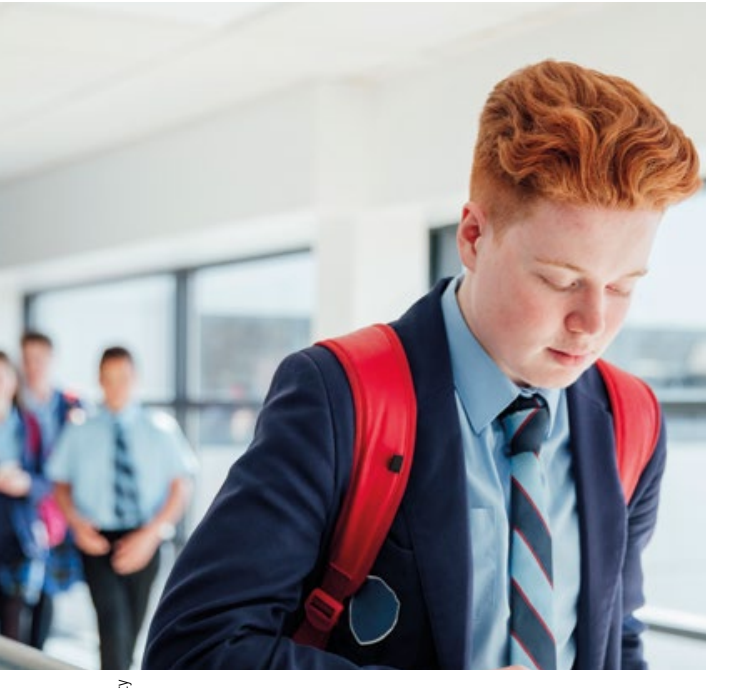

The British Dental Association (BDA) helcomed official confirmation from ${ }^{\odot}$ Public Health England that the vaccination programme against the human papillomavirus (HPV) will start in September 2019 for 12-13year-old boys, and has called on government to redouble its efforts on parent education, given the drop in uptake among females and rising profile of 'Anti-Vax' cvampaigners.

A member of the HPV Action campaign coalition, the BDA had pressed for extension given the surge in oral cancer rates fuelled by the virus. It has insisted that promotional materials seek to counter the extreme and unfounded health scares featuring widely across social media.

Official data show that rates of uptake among girls for two doses of the vaccine fell from $86 \%$ in 2006 to $83.9 \%$ in 2018 , and remained consistently below the $90-95 \%$ levels required for herd immunity. While the national target of immunising $80 \%$ of girls is being met, there is wide variation in uptake between local authority areas. The condition is linked to $5 \%$ of all cancers worldwide, including some that affect only men.

Health Secretary Matt Hancock pledged in March to tackle the growth in anti-vax sentiment via legislation. He said: 'we are working to tackle vaccine misinformation ... by reducing its distribution and providing people with authoritative information on the topic.'

The BDA is seeking assurances the plans for HPV vaccination will be properly resourced and take a robust approach where necessary. The high visibility campaigning that surrounded the female HPV vaccination programme at launch in 2008 has tailed off, with parents and schools currently able to access a small range of downloadable resources.

Recent cases have emerged of anti-vax leaflets snuck into children's books sold via Amazon warehouses, including baseless claims of the Gardasil vaccine 'causing injury, infertility, paralysis ... ovarian failure and death, amongst other conditions. Social media is awash with content falsely linking the vaccine to conditions including brain damage, Complex Regional Pain Syndrome (CRPS) and Postural Orthostatic Tachycardia Syndrome (POTS). Panic over such claims saw the vaccination rate in Japan drop to less than $1 \%$ from a high point of over $70 \%$.

The BDA has called for a catch-up programme for older boys while they are still in school. Failure to pursue this policy, applied when the programme was first introduced to girls, will leave up to two million boys across the UK unprotected.

\section{Dismay at lack of catch-up programme} The Faculty of General Dental Practice (FGDP([UK]) has reacted with dismay to the government's decision to deny immunisation against human papillomavirus (HPV) to a million schoolboys.

Public Health England (PHE) has announced that the new HPV vaccination programme for 12-13-year-old (Year 8) boys will start in the school year beginning this September, but also confirmed that it will not offer a catch-up programme to boys in Years 9-13.

While the implementation of vaccination for Year 8 boys in 2019 protects one more year group than a delay to 2020 would have done, the decision not to offer a catch-up programme leaves five older year groups in England - around a million boys - vulnerable to HPV-related cancers in later life, while the girls in their class are protected.

FGDP(UK) Dean, Ian Mills said: 'The opportunity must be seized to vaccinate as many boys as possible while they are still at school, and the government's decision not to do so in England is dissonant with its recent trailing of a green paper on preventative healthcare. I only hope that Scotland, Wales and Northern Ireland decide to do the right thing and protect all their schoolchildren when implementing their own programmes.'

\section{Celebrate 25 years of BOS in Glasgow}

Next month's British Orthodontic Conference being held at the SEC in Glasgow on 19-21 September promises something for everyone.

Highlights of the programme include:

- Acclaimed IVF pioneer Professor Robert Winston will be delivering a keynote presentation on the Thursday, asking 'Can we achieve happiness?'

- The prestigious Northcroft memorial lecture will be presented by Professor Greg Huang from Washington State University on 'Results from the
NDPBRN Adult Anterior Open-bite Study'

- Jay Bowman from the US will be delivering two sessions: 'Uno, Dos, Tres: All miniscrews in one place (mostly)'; and 'Drastic Plastic: Improving the predictability of clear aligners'

- Peter Miles from Australia will be presenting on 'The agony and ecstasy of Invisalign'

- Former MP Lembit Opik will be alongside Michael Millwaters and Pratik Sharma discussing his orthognathic case and experience.
There is also a parallel session on 'Driving Your Private Practice' with many speakers including Chris Barrow, Magali Mujagic, Claire Nightingale and Peter Huntley.

2019 marks the 25th anniversary of the British Orthodontic Society (BOS) and there will be much celebration at the conference.

For a full speaker programme, visit https://www.bos.org.uk/BOC-Glasgow2019-Programme. To book visit https:// www.bos.org.uk/BOC-Glasgow-2019. A combined dental team rate is available. 